\title{
P01 - Sensitisation pattern to inhalant allergens in Armenian children
}

\author{
${\text { Astghik Baghdasaryan }{ }^{1 *}, \text { Ashot Sarkissian}^{1}, \text { Ernst Leumann², Roger Lauener }}^{2}$ \\ From 3rd Pediatric Allergy and Asthma Meeting (PAAM) \\ Athens, Greece. 17-19 October 2013
}

\section{Background}

Pediatric respiratory allergies are increasing problem in Armenia being underestimated according to official reports. "Allergic Sensitization and Diseases in Armenian Children" study has been conducted to assess the prevailing sensitizations to inhalant allergens of Armenia using the standardized panel and method of PEP study (Pan-European standard Skin prick test study) conducted by Global Allergy and Asthma European Network (GA2LEN).

\section{Objectives}

To reveal prevailing sensitizations to inhalant allergens in Armenian children presenting atopy with a standardized method for diagnosis (developed by GA2LEN for European Centers), and to compare the obtained data with participant countries of PEP project.

\section{Materials and methods}

A total of 231 children aged 2-18 years applied to "Arabkir" $\mathrm{MC}$ with previous history or suspicion of atopy were evaluated for sensitization to inhalant allergens using standardized prick test method, allergen solutions and panel. Additional allergen (Poplar) was used for Armenia. Data were saved and analyzed in SPSS software.

\section{Results}

192 (83\%) of all investigated children had sensitization to at least 1 allergen. 31 (13\% of all) children had monosensitization, $161(70 \%)$ had polysensitization up to maximum 12 allergens. The most prevalent allergen in Armenia, as in Europe, was the grass mix: 115 (49.8\%). In comparison to European countries, where Birch pollen was the $3^{\text {rd }}$ important allergen, tree pollen allergens were less important for Armenia: the most prevalent one was the plane
13.4\% (31). 10 allergens allowed identification of more than $95 \%$ of sensitized subjects (grass mix, Dermatophagoides pteronyssinus, dog, Alternaria, Plane, Artemisia, Hazel/Olive (or Ash), Cat/ Dermatophagoides farinae). 12 allergens were needed to identify all sensitized children (grass mix, Dermatophagoides pteronyssinus, dog, Alternaria, Plane, Artemisia, Hazel/Olive (or Ash), Cat/Dermatophagoides farinae, Cladosporium/ Poplar).

\section{Conclusions}

The most important inhalant allergen in Armenia was grass pollen. 10 allergens allowed the identification of the majority of sensitized children.

\section{Authors' details \\ "Arabkir" Joint Medical Centre-Institute of Child and Adolescent Health ("Arabkir" JMC-ICAH), Yerevan, Armenia. ${ }^{2}$ Zurich University Children's Hospital, Zurich, Switzerland.}

Published: 28 February 2014

\section{doi:10.1186/2045-7022-4-S1-P56}

Cite this article as: Baghdasaryan et al: P01 - Sensitisation pattern to inhalant allergens in Armenian children. Clinical and Translational Allergy 2014 4(Suppl 1):P56.

"Arabkir" Joint Medical Centre-Institute of Child and Adolescent Health

("Arabkir" JMC-ICAH), Yerevan, Armenia

Full list of author information is available at the end of the article

(c) 2014 Baghdasaryan et al; licensee BioMed Central Ltd. This is an Open Access article distributed under the terms of the Creative Commons Attribution License (http://creativecommons.org/licenses/by/2.0), which permits unrestricted use, distribution, and reproduction in any medium, provided the original work is properly cited. The Creative Commons Public Domain Dedication waiver (http://creativecommons.org/publicdomain/zero/1.0/) applies to the data made available in this article, unless otherwise stated. 